\title{
Common variable immunodeficiency - case report
}

\author{
BOLESŁAW KALICKI ${ }^{l}$, KAROLINA KAPUSTA ${ }^{l}$, ANNA ŚNIADY', \\ EDYTA HEROPOLITANSSKA-PLISZKA ${ }^{2}$, ANNA MIERZEJEWSKA ${ }^{l}$, ANNA JUNG $^{l}$
}

${ }^{1}$ Department of Pediatrics, Pediatric Nephrology and Allergy, Military Institute of Medicine, Warsaw, Poland

${ }^{2}$ Department of Immunology, The Children's Memorial Health Institute, Warsaw, Poland

\begin{abstract}
Immunodeficiencies in clinical practice are relatively rare. The most common cause worldwide is HIV infection, both in children and adults. Among primary immunodeficiencies the most frequent one is IgA deficiency (IgAD), followed by CVID (common variable immunodeficiency). This paper describes a case report of a 14-year-old girl, raising the problem of CVID occurence in day-to-day medical practice. Typically the disease appears between the ages of 5-10 and 20-40. In 70-80\% of patients the main manifestations are recurrent respiratory infections - pneumonia, bronchitis and sinusitis. Gastroenteritis and inflammatory bowel disease (IBD) also occur. Autoimmune diseases are present in $20 \%$ of patients, lymphadenopathy and splenomegaly can also be observed. Malignancy occurs 5 times more often when compared to the general population. Due to a diverse clinical manifestation, the diagnosis of CVID is usually greatly delayed, which may lead to serious complications such as bronchiectasis or pulmonary heart disease. The etiopathogenesis of CVID is not fully known. The main treatment consists of life-long immunoglobulin substitution in intravenous or subcutaneous form.
\end{abstract}

Key words: primary immunodeficiencies, hypogammaglobulinaemia, common variable immunodeficiency, lymphadenopathy, $\gamma$-globulins.

(Centr Eur J Immunol 2013; 38 (1): 141-148)

\section{Introduction}

The problem of recurrent infections is a big challenge for both pediatricians and general practitioners. Recurrent pneumonia and bronchitis, prolonged, unresponsive to standard treatment sinusitis or otitis should catch the doctor's attention and prompt him to differential diagnosis towards primary immunodeficiencies (PIDs). Such disorders occur in clinical practice very rarely, but they shouldn't be missed as early diagnosis allows for rapid implementation of treatment and avoidance of complications. Clinical picture of PIDs can vary from mild to severe cases, even within the same disease in two different patients. IgA deficiency (IgAD) is the most common primary immunodeficiency and is characterized by undetectable levels of serum IgA (less than $0.06 \mathrm{~g} / \mathrm{l}$ ), usually asymptomatic course and a normal life expectancy [1]. Severe Combined Immunodeficiency (SCID) has the most severe course among the all congenital defects of the immune system. The striking characteristic is usually lymphopenia with a severe defect in both the T- \& B-lymphocyte subsets. Life expectancy of patients with SCID is typically less than 2 years of age, mainly due to severe, life-threatening infections and their complications $[2,3]$.

This article concerns the second most common PID common variable immunodeficiency (CVID). It is essential to determine if there is a family history of PID, draw attention to the current course and the rate of infection, the effectiveness of their treatment, and evaluation of physical and psychological development of the child. The physical examination should be carried out very carefully and it requires a thorough evaluation of the skin, mouth, joints and all organs, with particular emphasis on the elements of the immune system [1].

Common variable immunodeficiency frequency varies from $1: 10000$ to $1: 50000$, the diagnosis is based on 
a reduced level of $\mathrm{IgG}$ and $\mathrm{IgA}$ and/or IgM, which is a consequence of impaired B cell development [4]. Deregulation of the immune system, leading to hypogammaglobulinemia, defective activation and proliferation of $\mathrm{T}$ cells and dendritic cells, and malfunction of the cytokines are observed in CVID [5]. Age at CVID diagnosis varies between 5 and 72 years of age; typically, the disease manifests itself between 5 and 10 years of age and between 20 and 40 years of age [6]. The clinical picture is not distinctive, and the symptoms may be difficult to detect on the clinical level [7]. 70\% to $80 \%$ of patients suffer from recurrent respiratory infections (pneumonia, bronchitis, sinusitis). There are also additional diseases, including infections or inflammatory diseases of the gastrointestinal tract, lymphadenopathy, splenomegaly and autoimmune diseases [5]. Due to the diversity of the clinical picture and a low incidence of CVID, the diagnosis is often delayed - in children about 2.5 years, in adults - even up to 5.5 years [8]. This situation poses a real threat to both the short-term and longterm prognosis.

Genetic basis of CVID is still unknown [1]. Similarly, the pathogenesis of autoimmunity remains unclear. $20 \%$ of patients with CVID suffer from autoimmune diseases, mainly thrombocytopenic purpura and autoimmune hemolytic anemia [9]. Rheumatoid arthritis, juvenile idiopathic arthritis, systemic lupus erythematosus, primary biliary cirrhosis, and vitiligo are also significantly more common among these patients [10-12]. In recent years, enormous progress has been made in the genetic and immunological diagnosis of primary immunodeficiencies. Today we know the genetic cause of more than 130 syndromes [1].

Constantly improving treatment gives a chance for a normal life to patients with PID. That is why it is so important to remember that the defects of the immune system are still present in the clinical reality.

\section{Epidemiology}

Human immunodeficiency virus (HIV) infection is the most common cause of immunodeficiency both in children and adults [13]. Therefore screening for HIV (anti-HIV antibodies detected by ELISA and HIV-RNA or HIV-cDNA by PCR - in the case of hypogammaglobulinemia) should always be considered when PID is suspected. Although PIDs are very rare diseases, doctors should not forget that antibody deficiencies, connected with B cells disfunction, comprise approximately $50 \%$ of cases [13]. In about $20 \%$ of cases we are dealing with both cellular and humoral disfunction. Common variable immunodeficiency (CVID) is the second most common, humoral immunodeficiency, occurring from $1: 25000$ to $1: 66000[14,15]$ and affecting both sexes equally. The most common PID - IgAD, being usually asymptomatic, makes CVID the most common primary immunodeficiency that requires medical intervention. CVID can occur in members of the same family in approximately $20 \%$ of cases [16]. There are also cases of progression of IgAD to CVID [17-20] and in casuistic cases - CVID to IgAD [21].

\section{Etiopathogenesis}

The proper response of immune system depends on many factors. The etiopathogenesis of CVID is complex and not fully understood. Due to the incidence of family cases of CVID, genetic background of immunodeficiency is suspected. There are numerous factors playing role in pathogenesis of CVID - abnormal B cell differentiation with impaired secretion of immunoglobulins, impairment of cooperation between the cells leading to abnormal differentiation of T cells $[22,23]$ and anomalies associated with the cytokines secretion.

\section{Clinical picture}

The clinical picture of CVID varies, any organ or system can be affected, therefore the diagnosis is often difficult and delayed. The most common presentation of CVID are recurrent, severe and prolonged infections. They are accompanied by a productive cough in many cases [24]. Recurrent infections include bacterial infection of the upper and lower respiratory tract: sinusitis, otitis media, bronchitis, and pneumonia (Table 1A,B). It is estimated that about $78 \%$ of patients underwent lower respiratory tract infection at least once before diagnosis of CVID [10]. Recurrent infections, poorly responding to conventional antibiotics, can lead to the formation of bronchiectasis, respiratory failure and cor pulmonale. Such a sequence of events in a number of cohort studies is estimated at $17-76 \%$ [24-33]. Early diagnosis usually protects the patient against this complication, however, development of bronchiectasis occurs even in $30 \%$ of patients, despite optimal treatment $[34,35]$.

The most common pathogens responsible for the majority of respiratory infections in patients suffering from CVID are encapsulated bacteria: Streptococcus pneumoniae and Haemophilus influenzae, but also Streptococcus pyogenes. Pseudomonas aeruginosa and Moraxella catarrhalis [3638]. Infections of the nervous system: meningitis, encephalities and brain abscesses may also be rare but life-threatening manifestation of CVID. They are usually caused by S. pneumoniae, $H$. influenzae, $S$. aureus [25, 38], but also by viral infections, especially enteroviruses [35]. CVID patients have a tendency to form granulomas, which conforms it to sarcoidosis [39]. Granulomas can occur in any organ, the most frequently in the respiratory tract, liver, and spleen, rarely in the kidney, brain, conjunctiva, and skin [35].

Digestive system is a vital element for the proper functioning of the immune system. In the course of CVID, both immunoglobulin production and response to continuous antigenic stimulation in the gastrointestinal tract do not work 
properly. Symptoms from the gastrointestinal tract are quite common in CVID and occur in 21 to $50 \%$ cases [10, 28, 38, 40]. Most patients suffer from diarrhea, both acute and chronic. Giardia lamblia, Campylobacter spp., Salmonella spp. and Shigella spp. play a statistically significant role in the etiology $[33,35,38,40]$. Giardiasis may manifest as diarrhea (watery or steatorrhea), spasmodic abdominal pain, bloating, and impaired nutritional status. In such cases, celiac disease should also be taken into consideration, however, serological diagnosis is usually negative (there is no detection of autoantibodies against tissue transglutaminase [tTG] or endomysium [EMA]). Histological examination of the intestinal mucosa cannot differentiate between these two diseases because in both cases flattening and loss of microvilli are observed. Therefore it is important, to perform a microscopic evaluation after gluten elimination diet. Only in $50 \%$ of the cases we get apparent regression of histological changes in CVID [41, 43]. Atrophic changes involve not only the small intestine, but also, in half of CVID patients, the stomach, resulting in a reduction in acid secretion. The clinical picture in this case is the same as in Addison-Biermer anemia but with negative serum autoantibodies [25, 28, 42].

CVID can cause inflammatory changes in any part of the digestive system and sometimes mimics Crohn's disease [24, 25, 28]. Inflammatory lesions are localized primarily in the small intestine, which in some cases leads to a significant deficiency of trace elements or vitamins A, D, $\mathrm{E}$, with visible consequences not only in skeletal system [44]. Changes involving brush border of the small intestine can sometimes reduce lactase activity, and hence cause lactose malabsorption, leading to osmotic diarrhea, bloating, abdominal pain, and , in consequence, loss of protein and fat, and then hypovitaminosis and malnutrition [45].

Increased rate of malignancy is another risk factor for patients with CVID. In two studied CVID populations malignancy is the leading cause of death [10, 40]. It is estimated that the risk of a malignant growth is about 5 times higher in a population of patients with CVID, compared to the general population [40, 46]. Although some studies show a smaller rate $(1.8 \times)$ [43], while others much bigger $(13 \times)$ incidence of malignancy [5]. Non-Hodgkin B cell lymphomas are listed among the most commonly reported cancers $[6,10,25]$. Their origin is connected with EBV infection resulting in polyclonal B-cell proliferation, which together with concomitant immunological defects leads to uncontrolled proliferation of B cells and the development of lymphoma [35, 40]. The genetic material of the virus is not always detected, so that its role in carcinogenesis in the primary hypogammaglobulinemia seems to be of minor importance [8]. In addition to malignant lymphatic hyperplasia in CVID, mild hyperplasia, characterized by lymphadenopathy and splenomegaly is often seen $[25,28,47]$. Unfortunately, there is also malignant transformation of epithelial tissues in CVID, especially in the gastric mucosa.
Table 1A. Problems suggesting immune deficiency disorders in children (for suspected immunodeficiency just one of the following) - by Zeman K, Szałowska D (2006): Primary immunodeficiencies-important group of rare genetic diseases. Pediatric Review 36: 251-257

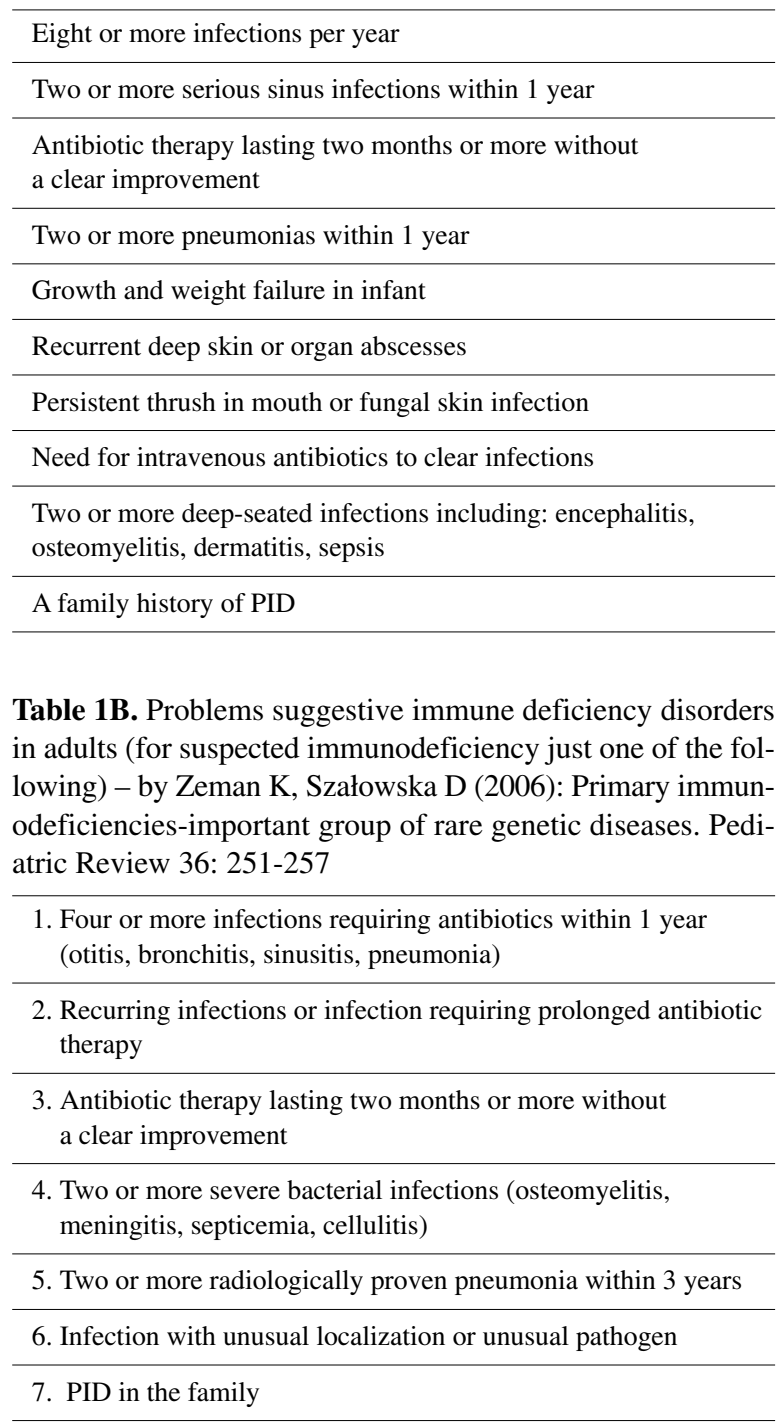

The risk of stomach cancer (adenocarcinoma) is up to 47 times higher than in the general population [46]. In these cases, achlorhydria, pernicious anemia and increased susceptibility to Helicobacter pylori infection play a role in the pathogenesis [35, 40]. Among other cancers related to CVID occurring in studies there are: Hodgkin's lymphoma, colon carcinoma and breast cancer [10].

CVID and selective IgA deficiency present with predominant autoimmune manifestation among primary immunodeficiency disorders. According to various statistics, about $10-20 \%$ of patients with CVID develop an autoimmune disease $[9,46]$. Haematological disorders predominate - immune thrombocytopenic purpura (ITP), 
autoimmune hemolytic anemia (AIHA) and Evans syndrome. Less commonly, the development of neutropenia and autoimmune lymphopenia can be observed [9, 10, 35, $38,49]$. In these conditions a possibility of CVID should alwys be considered [48, 49]. Other autoimmune disorders observed in patients suffering from CVID include: autoimmune thyroid disease (Graves' disease, Hashimoto's disease), juvenile idiopathic arthritis, rheumatoid arthritis, systemic lupus erythematosus, Sjögren's syndrome, primary biliary cirrhosis, alopecia and vitiligo [48]. The appropriate diagnosis of autoimmune disease in a patient with CVID is not easy as evaluation of typical auto-antibodies is usually negative, but in these conditions such result dose not exclude the disease.

\section{Diagnosis}

Correct diagnosis of immune deficiency is not easy, and sometimes is not always possible. It often requires quite detailed studies that are not available in routine diagnostics. However, the initial suspicion of immunodeficiency in a patient (Table 1) is possible at the level of every general practitioner. A careful investigation of past medical history is the first step in the diagnosis. It should be established when the first symptoms of immunodeficiency such as persistent, recurrent infections occur. Children up to 6 month of age possess maternally derived antibodies, therefore, in accordance with ESID criteria (Table 2) CVID can be recognized after 2 years of age. In addition to infections such as sinusitis, otitis media, bronchitis, pneumonia, or gastrointestinalis, the nutritional status of the patient should be evaluated. Unexplained weight loss is relatively common symptom in CVID. Past medical history should include the

Table 2. Criteria for the diagnosis of CVID by the European Society for the Immunodeficiencies (ESID)

\begin{tabular}{|c|}
\hline Diagnosis probable \\
\hline $\begin{array}{l}\text { Male or female patient who has a marked decrease of } \operatorname{IgG} \text { (at least } \\
2 \mathrm{SD} \text { below the mean for age) and a marked decrease in at least one } \\
\text { of the isotypes IgM or IgA, and fulfills all of the following criteria: }\end{array}$ \\
\hline - onset of immunodeficiency at greater than 2 years of age \\
\hline - absent isohemagglutinins and/or poor response to vaccines \\
\hline $\begin{array}{l}\text { - defined causes of hypogammaglobulinemia have been excluded } \\
\text { (Table 3) }\end{array}$ \\
\hline Diagnosis possible \\
\hline $\begin{array}{l}\text { Male or female patient who has a marked decrease (at least } 2 \text { SD } \\
\text { below the mean for age) in one of the major isotypes (IgM, IgG } \\
\text { and } \operatorname{IgA} \text { ) and fulfills all of the following criteria: }\end{array}$ \\
\hline - onset of immunodeficiency at greater than 2 years of age \\
\hline - absent isohemagglutinins and/or poor response to vaccines \\
\hline - defined causes of hypogammaglobulinemia have been excluded \\
\hline
\end{tabular}

presence of autoimmune diseases. Also very important is the knowledge of the possible occurrence of immunodeficiency in relatives.

The physical examination is necessary to assess nutritional status, and current development. The most common problems occurring in the physical examination in a CVID patient include: conjunctivitis, sinusitis, otitis media, auscultatory lungs changes, lymphadenopathy, hepatosplenomegaly (Table 4). The basic laboratory tests including blood count with blood smear together with proteinogram are the second step in the diagnosis of the patient. The second test shows a reduction in serum gamma- globulin fraction and the need for further evaluation of the major classes of immunoglobulins. CVID diagnosis according to the criteria shown in Table 2, can be made only after exclusion of secondary causes leading to decreased levels of serum antibodies (Table 3). Therefore, it is necessary to perform additional tests for the exclusion of other diseases leading to hypogammaglobulinemia. Serum immunoglobulins (IgG, IgA, IgM) should be assessed in each patient. Decrease of IgG (at least 2 SD below the mean for age) and a marked decrease in at least one of the isotypes $\operatorname{IgM}$ or $\operatorname{IgA}$ suggest CVID. The assessment of isohemagglutinin titer is another criteria for diagnosis of CVID which indicate abnormal function of IgM. The blood group AB, naturally dose not have any isohemaglutinins. In such cases, in order to identify CVID, we should evaluate function of B cells for antibody production, for example after immunization with protein antigens (tetanus, diphtheria) or polysaccharide antigen (S. pneumoniae). Immune response to polysaccharide antigens develop between 2 and 4 years of age therefore it should be evaluated after 5 years of age. In CVID poor resonse to all type of vaccines is observed. The next step in diagnosis is to perform cytometric analysis for the identification of subpopulations of lymphocytes. Typically, the number and percentage of B cells is normal or slightly reduced, despite hypogammaglobulinemia [47]. Further diagnosis includes cytometric examining of of B cells maturation in the peripheral blood and bone marrow as well as mutations in ICOS, TACI, CD19, BAFF-R genes.

\section{Treatment}

The mainstay of treatment of patients with CVID is substitution of immunoglobulins (Ig). The first prophylactic administration of Ig took place in 1952. The patient, a 8year-old boy received $3.2 \mathrm{~g}$ of concentrate intramuscularly monthly [49]. Currently Ig is administered intravenously (IVIG) or subcutaneously (SCIG). Intravenous infusions are repeated every month due to the average half-life of IgG antibody of about 3-4 weeks. Subcutaneous supply of immunoglobulin is administered once a week, and has many advantages compared to the intravenous route: it allows to treat patient at home, has a lower price, allows to maintain a high and stable levels of antibodies in the blood. Monthly 
Table 3. Differential diagnosis of hypogammaglobulinemia

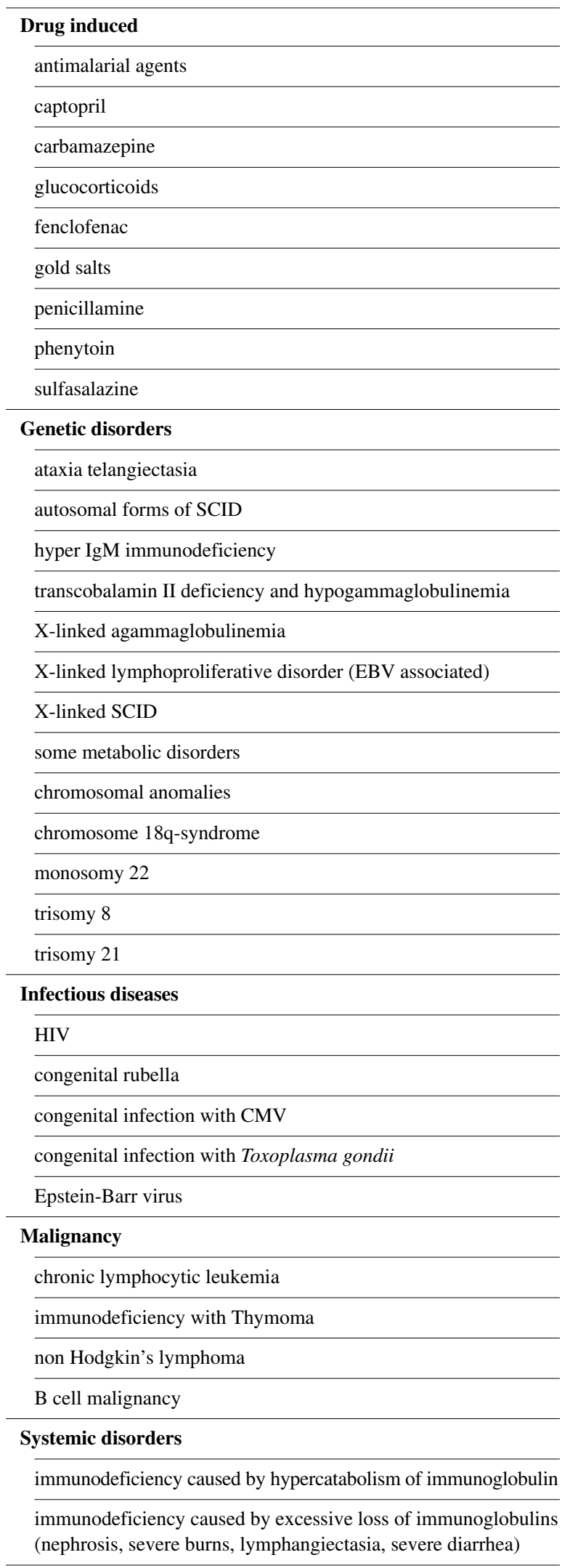

Table 4. The most common disorders occurring in CVID

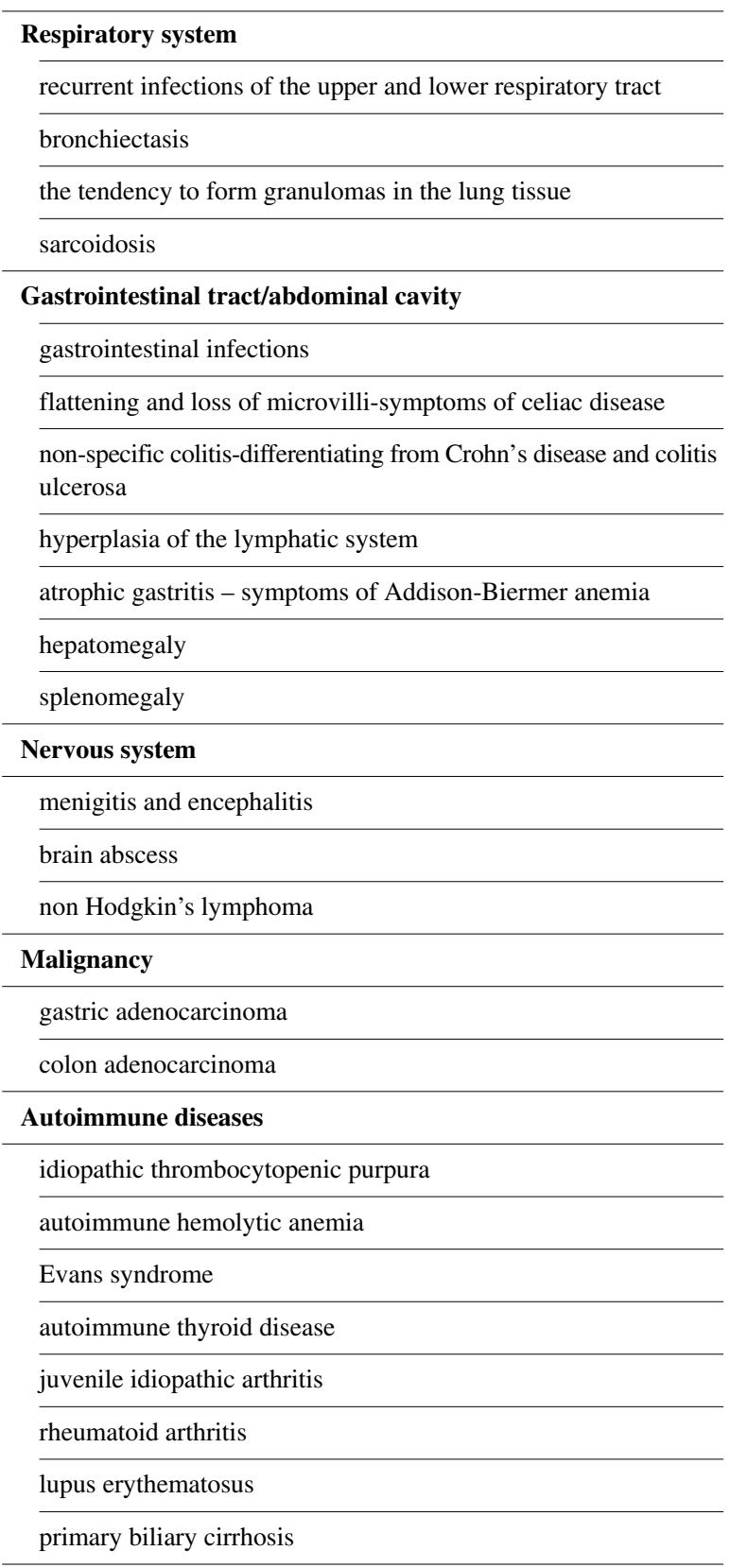

Ig dose administered intravenously is $0.4-0.8 \mathrm{~g} / \mathrm{kg}$, while weekly Ig dose administered subcutaneous is $0.1-0.2 \mathrm{~g} / \mathrm{kg}$. The treatment is life-long and should ensure IgG level from 5 to $8 \mathrm{~g} / \mathrm{l}$, whereas in patients with bronchiectasis, even 7 to $8 \mathrm{~g} / \mathrm{l}$. Regular IVIG/SCIG can reduce the incidence of infection, and thus severe complications. Prevention is very important. Patients with PID should avoid contact with infected people, potential sources of infection, follow the rules of hygiene, care for oral health, use a balanced and varied diet and vitamin supplements. If, despite such interventions, the patient developes infection, it should be treated in 
a hospital and given intravenous drugs. Treatment must be prolonged as compared to the typical procedure and last for several weeks or even months. Antibiotics from different groups together with a combination of antifungal and antiviral drugs are used in such cases [1]. In some cases, antibiotic prophylaxis may be used: amoxicillin at a daily dose of $20 \mathrm{mg} / \mathrm{kg}$ or azithromycin 3 times a week at half of the therapeutic dose [50]. The general rule is not to vaccinate the PID patient with live vaccines, but the issue is much more complicated, and each form of PID requires an individual consideration and decision. In CVID recommend vaccination against $S$. pneumoniae, $H$. influenzae type $B$ and $N$. meningitidis, should be carried out prior to the first infusion of Ig [1]. Patients suffering from this rare disorder of the immune system need a multi-profile medical care as well as the strong commitment and self-awareness of the problem.

\section{Case report}

A 14-year-old girl, A.I., medical history number 51410, 55329, born from the first pregnancy, delivered naturally,

Table 5A. The level of the individual classes of immunoglobulins in the patient compared to normal age-matched levels

\begin{tabular}{lcc}
\hline Classes of immunoglobulins & Level in patient & Normal level \\
\hline $\mathrm{IgG}$ & $205(\mathrm{mg} / \mathrm{dl})$ & $682-1500$ \\
\hline $\mathrm{IgA}$ & $<7(\mathrm{mg} / \mathrm{dl})$ & $60.0-304.0$ \\
\hline $\mathrm{IgM}$ & $46(\mathrm{mg} / \mathrm{dl})$ & $52-321$ \\
\hline $\mathrm{IgE}$ & $<2(\mathrm{IU} / \mathrm{ml})$ & $10.0-135.0$ \\
\hline
\end{tabular}

on time, body weight $3550 \mathrm{~g}$, Apgar - 10 points, blood group $\mathrm{B} \mathrm{Rh}+$ was admitted to the Department of Paediatrics, Nephrology and Allergology, Military Institute of Medicine in Warsaw for diagnostics of recurrent respiratory infections. As a child the girl developed properly, height and weight was ranged around 97 percentile. The patient was vaccinated according to the polish vaccination schedule, no additional vaccinations were given. Since the start of pre-school she was suffering from mild upper respiratory infections about 10 times a year, bronchitis 3 times a year, tonsilitis twice a year, otitis media - once a year. During the school period infection rate remained at the same level. At the age of 11 chronic cough appeared. The girl was suspected of developing asthma, however the results of skin prick tests and spirometry were normal. In June 2011, the patient underwent adenectomy and tonsillotomy, what increased episodes of infection. In February 2012 the girl was hospitalized in another hospital because of pneumonia accompanied by fever up to $40^{\circ} \mathrm{C}$. She was treated with cefotaxime (Claforan), clarithromycin (Klacid). In July 2012 a child was again hospitalised because of chest pain, escalating when breathing, cough, and fever up to $38^{\circ} \mathrm{C}$. The physical examination revealed sore throat, inflammatory markers were elevated. Chest X-ray was performed and the diagnosis of right-sided pneumonia was established. Computed tomography of the chest was performed due to reccurrency of lung changes, which confirmed the diagnosis of pneumonia. The sinus $\mathrm{X}$-ray revealed mucosal wall thickening in the maxillary sinus. The patient was efficiently treated with ceftriaxone (Ceftriaxone) and clarithromycin (Klacid). The patient was discharged home with recommendations to continue therapy.

Table 5B. Titer of antibodies after immunization against diphtheria and tetanus in the serum tested by ELISA

\begin{tabular}{lcc}
\hline Tested feature & Result & Manufacturer's recommendations \\
\hline $\begin{array}{l}\text { titer of antibodies after immunization against tetanus in a serum } \\
\text { sample determined by ELISA immunoenzymatic reaction (IU/ml) }\end{array}$ & 0.04 & $\begin{array}{l}\text { uncertain protection, revaccination recommend immediately } \\
\text { and follow-up after 4-8 weeks after immunization }\end{array}$ \\
\hline $\begin{array}{l}\text { titer of antibodies after immunization against diphtheria } \\
\text { in a serum sample determined by ELISA immunoenzymatic } \\
\text { reaction }(\mathrm{IU} / \mathrm{ml})\end{array}$ & $<0.08$ & primary immunization recommended immediately \\
\hline
\end{tabular}

Table 5C. Lymphocyte subpopulations (T, B, NK cells) - the percentage and absolute number of cells in a patient compared to normal for age

\begin{tabular}{lcccc}
\hline Lymphocytes & $\begin{array}{c}\text { Percentage } \\
\text { of cells }(\boldsymbol{\%})\end{array}$ & $\begin{array}{c}\text { Normal } \\
\text { percentage }(\boldsymbol{\%})\end{array}$ & $\begin{array}{c}\text { Absolute number } \\
(\text { cells/ } \boldsymbol{\mu l})\end{array}$ & $\begin{array}{c}\text { Normal absolute } \\
\text { number }(\text { cells/ } \boldsymbol{\mu l})\end{array}$ \\
\hline CD45+/Scc low & - & - & 2216 & $1500-3900$ \\
\hline CD3+/CD45+ & 75.4 & $52.9-79.1$ & 1671 & 1123 \\
\hline CD3+CD8+/CD45+ & 50.7 & $18.2-33.2$ & 441 & $300-1100$ \\
\hline CD3+CD4+/CD45+ & 19.9 & $27.4-54.3$ & 127 & $500-1600$ \\
\hline CD16+56+CD3-/CD45+ & 5.7 & $5.2-28.6$ & 415 & $100-830$ \\
\hline CD19+/CD45+ & 18.7 & $9.4-22.8$ & $200-600$ \\
\hline
\end{tabular}


On admission to the Department of Paediatrics, Nephrology and Allergology physical examination revealed nasal obstruction and coated tongue. The girl reported abdominal pain occurring from time to time, a feeling of heartburn and unpleasant smell from the mouth. Markers of inflammation were slightly elevated [CRP $2.8 \mathrm{mg} / \mathrm{dl}$ $(\mathrm{N}<0.8)$, OB: $4 \mathrm{~mm}$ after 1 hour $(\mathrm{N}<12)$ ], complete blood count with differential, without deviation [WBC: 5.96 $\left(\times 10^{9} / 1\right)(\mathrm{N}: 4.0-10.0)$, lymph: $23.8 \%$, NEUT: $66.4 \%$, MONO: 6\%, EO: $1.4 \%$, BASO: 0.1\% RBC: $4.99\left(\times 10^{12} / 1\right)$ (N: 3.5-5.5), HGB: $14 \mathrm{~g} / \mathrm{dl}(\mathrm{N}: 11.0-18.0)$, PLT: $195\left(\times 10^{9} / \mathrm{l}\right)$ (N: 150-400)]; mononucleosis latex test was negative, ASO was not elevated, there was also no evidence of active infection with cytomegalovirus. Other tests - indicators of liver and kidney functions were normal, there were no electrolyte abnormalities. Urin analysis revealed no features of infection. Abdominal ultrasound was also normal. She was diagnosed with chronic sinusitis and gastroesophageal reflux disease. Due to recurrent infections, particularly two episodes of pneumonia in short period of time, evaluation of immunoglobulins ( $\operatorname{IgG}, \operatorname{IgA}, \operatorname{IgM}, \operatorname{IgE}$ ) was made. It revealed significant decreased levels of all isotypes in two repeated tests (Table $5 \mathrm{~A}$ ).

The concentration of immunoglobulins in the patient's parents were normal. The child was again taken to the hospital for further evaluation and transfusion of immunoglobulins. On admission physical examination revealed symptoms of infection: enlarged tonsils, enlarged, hard, painless, cervical and axillary lymph nodes. Chest X-ray revealed signs of bronchitis. Before IVIG substitution, the antibodies titers after diphtheria and tetanus immunization (Table 5B) were measured and anti-HBs level was $<2$ IU/l. The isohemagglutinins were undetectable. During first IVIG replacement side effects in the form of tremor, abdominal pain and skin marbling were observed. Pressure and heart rate were difficult to determine. Due to probable allergic reactions immunoglobulin infusion was discontinued and the girl was transferred to the Department of Immunology The Children's Memorial Health Institute.

Further diagnosis included the study of peripheral blood lymphocytes using flow cytometry and evaluation of the percentage and absolute number of individual subpopulations of lymphocytes showed no significant deviations (Table 5C), However, the analysis of B cells (CD19+/ $\mathrm{CD} 45+)$ development in peripheral blood revealed remarkable abnormalities. On the basis of clinical picture and the exclusion of other causes of hypogammaglobulinemia the patient was diagnosed with common variable immunodeficiency (CVID).

The aim of the paper is to emphasize the need to perform basic laboratory tests and to determine immunoglobulin classes in clinical practice in patients with recurrent infections. The abnormalities in these widely available tests should prompt to extend the diagnosis and allow for the early detection of disorders of the immune system.

\section{References}

1. Pietrucha B, Heropolitańska-Pliszka E, Klaudel-Dreszler M, et al. (2011): Selected issues in clinical immunology - humoral and cellular deficiencies (Part I). Pediatr Pol 86: 548-558.

2. Rich R, Fleisher A, Shearer T, et al. Clinical Immunology principles and practice. Mosby-Year, St. Louis 2001.

3. Chapel H, Haencey M, Misbak S, et al. (2006): Essentials of clinical Immunology, Blackwell Publishing Ltd.

4. Geha RS, Notarangelo LD, Casanova JL, et al. (2007): Primary immunodeficiency diseases: an update from the International Union of Immunological Societies Primary Immunodeficiency Diseases Classification Committee. J Allergy Clin Immunol 120: 776-794.

5. Agarwal S, Cunningham-Rundles C (2009): Autoimmunity in common variable immunodeficiency. Curr Allergy Asthma Rep 9: 347-352.

6. Cunningham-Rundles C, Lieberman P, Hellman G, et al. (1991): Non-Hodgkin lymphoma in common variable immunodeficiency. Am J Hematol 37: 69-74.

7. Knight AK, Cunningham-Rundles C (2006): Inflammatory and autoimmune complications of common variable immune deficiency. Autoimmun Rev 5: 156-159.

8. Gompels MM, Hodges E, Lock RJ, et al. (2003): Lymphoproliferative disease in antibody deficiency: a multi-centre study. Clin Exp Immunol 134: 314-320.

9. Cunningham-Rundles C (2008): Autoimmune manifestations in common variable immunodeficiency. J Clin Immunol 28 (Suppl 1): 42-45.

10. Cunningham-Rundles C, Bodian C (1999): Common variable immunodeficiency: clinical and immunological features of 248 patients. Clin Immunol 92: 34-48.

11. Quinti I, Soresina A, Spadaro G, et al. (2007): Long-term follow-up and outcome of a large cohort of patients with common variable immunodeficiency. J Clin Immunol 27: 308-316.

12. Wang J, Cunningham-Rundles C (2005): Treatment and outcome of autoimmune hematologic disease in common variable immunodeficiency (CVID). J Autoimmun 25: 57-62.

13. Dizon JG, Goldberg BJ, Kaplan MS (1998): How to evaluate suspected immunodeficiency. Pediatric Ann 27: 743-750.

13. Stiehm ER (1996): Immunologic Disorders in Infants and Children. 4th ed. W.B. Saunders, Philadelphia.

14. Czyżewska-Buczyńska A, Lewandowicz-Uszyńska A, Jankowski A (2007): IgA important part of the immune system selected issues. Postępy Hig Med Dośw 61: 38-47.

15. IUIS (1999): Primary immunodeficiency diseases. Report of an IUIS Scientific Committee. International Union of Immunological Societies. Clin Exp Immunol 118 Suppl. 1: 1-28.

16. Hammarström L, Vorechovsky I, Webster D (2000): Selective IgA deficiency (SIgAD) and common variable immunodeficiency (CVID). Clin Exp Immunol 120: 225-231.

18. Johnson ML, Keeton LG, Zhu ZB, et al. (1997): Age-related changes in serum immunoglobulins in patients with familial IgA deficiency and common variable immunodeficiency (CVID). Clin Exp Immunol 108: 477-483.

17. Espanol T, Catala M, Hernandez M, et al. (1996): Development of a common variable immunodeficiency in IgA deficient patients. Clin Immunol Immunopathol 80: 333-335.

18. Gutierrez MG, Kirkpatrick CH. (1997): Progressive immunodeficiency in a patient with IgA deficiency. Ann Allergy Asthma Allergy 79: 297-301.

19. Seligmann M, Aucouturier P, Danon F, Preud'homme JL (1991): Changes in serum immunoglobulin patterns in adults 
with common variable immunodeficiency. Clin Exp Immunol 84: 23-27.

20. Mohammadi J, Jarefors S, Aghamohammadi A, et al. (2008): Genetic association in familial common variable immunodeficiency and IgA deficiency. Clin Exp Immunol 154 (suppl 1).

21. Szczawińska-Popłonyk A (2009): New insights into the pathogenesis of common variable immunodeficiency. Alergia Astma Immunologia 14: 230-238.

22. Thickett KM, Kumararatne DS, Banerjee AK, et al. (2002): Common variable immune deficiency: respiratory manifestations, pulmonary function and high-resolution CT scan findings. Q J Med 95: 655-662.

23. Hermaszewski RA, Webster AD (1993): Primary hypogammaglobulinaemia: a survey of clinical manifestations and complications. Q J Med 86: 31-42.

24. Seymour B, Miles J, Haeney M (2005): Primary antibody deficiency and diagnostic delay. J Clin Pathol 58: 546-547.

25. Kainulainen L, Varpula M, Liippo K, et al. (1999): Pulmonary abnormalities in patients with primary hypogammaglobulinemia. J Allergy Clin Immunol 104: 1031-1036.

26. Kainulainen L, Nikoskelainen J, Ruuskanen O (2001): Diagnostic findings in 95 Finnish patients with common variable immunodeficiency. J Clin Immunol 21: 145-149.

27. Watts WJ, Watts MB, Dai W, et al. (1986): Respiratory dysfunction in patients with common variable hypogammaglobulinemia. Am Rev Respir Dis 134: 699-703.

28. Dukes RJ, Rosenow EC 3rd, Hermans PE (1978): Pulmonary manifestations of hypogammaglobulinaemia. Thorax 33: 603-607.

29. Martínez García MA, de Rojas MD, Nauffal Manzur MD, et al. (2001): Respiratory disorders in common variable immunodeficiency. Respir Med 95: 191-195.

30. Bates CA, Ellison MC, Lynch DA, et al. (2004): Granulomatous-lymphocytic lung disease shortens survival in common variable immunodeficiency. J Allergy Clin Immunol 114: 415-421.

31. Llobet MP, Soler-Palacin P, Detkova D, et al. (2009): Common variable immunodeficiency : 20-yr experience at single centre. Pediatr Allergy Immun 20: 113-118.

32. Metersky ML (2012): The initial evaluation of adults with bronchiectasis. Clin Chest Med 2012; 33: 219-231.

33. Webster AD (2004): Clinical and immunological spectrum of common varable immunodeficiency. Iran J Allergy Asthma Immunol 2004; 3: 103-113.

34. Kainulainen L, Nikoskelainen J, Vuorinen T, et al. (1999): Viruses and bacteria in bronchial samples from patients with primary hippogammaglobulinemia. Am J Respir Crit Care Med 159: 1199-1204.

35. de Gracia J, Vendrell M, Alvarez A, et al. (2004): Immunoglobulin therapy to control lung damage with common variable immunodeficiency. Int Immunopharmacol 4: 745-753.

36. Oksenhendler E, Gérard L, Fieschi C, et al. (2008): Infections in 252 patients with common variable immunodeficiency. Clin Infect Dis 46: 1547-1554

37. Leen CL, Bath JC, Brettle RP, Yap PL (1985): Sarcoidosis and primary hypogammaglobulinaemia: a report of two cases and a review of the literature. Sarcoidosis 2: 91-95.

38. Kalha I, Sellin JH (2004): Common variable immunodeficiency and the gastrointestinal tract. Curr Gastroenterol Rep 6: 377-383.

39. Heneghan MA, Stevens FM, Cryan EM, et al. (1997): Celiac sprue and immunodeficiency states: a 25 -year review. J Clin Gastroenterol 25: 421-425.
40. Lai Ping So A, Mayer L (1997): Gastro intestinal manifestation of primary immunodeficiency disorders. Semin Gastrointest Dis 8: 22-32.

41. Mellemkjaer L, Hammarstrom L, Andersen V, et al. (2002): Cancer risk among patients with IgA deficiency or common variable immunodeficiency and their relatives: a combined Danish and Swedish study. Clin Exp Immunol 130: 495-500.

42. Cunningham-Rundles C (2010): How I treat common variable immune deficiency. Blood 116: 7-15.

43. Teahon K, Webster AD, Price AB, et al. (1994): Studies on the enteropathy associated with primary hypogammaglobulinaemia. Gut 35: 1244-1249.

44. Primary Immunodeficiency Diseases: Definition, Diagnosis, and Management. Rezaei N, Aghamohammadi A, Notarangelo LD (eds.). Springer, Berlin 2008.

45. Cunningham-Rundles C, Siegal FP, Cunningham-Rundles S, Lieberman P (1987): Incidence of cancer in 98 patients with common varied immunodeficiency. J Clin Immunol 7: 294-299.

46. Mohammadinejad P, Aghamohammadi A, Abolhassani H, et al. (2012): Pediatric patients with common variable immunodeficiency: long-term follow-up. J Investig Allergol Clin Immunol 22: 208-214.

47. Mikołuć B, Pietrucha B, Motkowski R, et al. (2009): Zapobieganie zakażeniom w pierwotnym i wtórnym niedoborze przeciwciał. Przegl Epidemiol 63: 55-60.

48. Blore J, Heany M (1989): Primary antibody deficiency and diagnostic delay. Br Med J 298: 516-517.

49. Sneller MC, Strober W, Eisenstein E, et al. (1993): New insights into common variable immunodeficiency. Ann Intern Med 118: 720-730.

50. Serisier DJ, Martin ML (2011): Long-term, low-dose erythromycin in bronchiectasis subjects with frequent infective exacerbations. Respir Med 28: 946-949.

51. Zeman K, Szałowska D (2006): Primary immunodeficienciesimportant group of rare genetic diseases, Pediatric Review 36 : 251-257. 